\title{
Sleep quality and suicidal behavior in euthymic bipolar patients
}

\author{
Qualidade do sono e comportamento suicida em pacientes \\ bipolares eutímicos
}

\begin{abstract}
Sleep disturbances in general - most notably insomnia - are associated with suicidal ideation as well as suicide attempt in both clinical and non-clinical samples. Such associations remain significant even after the adjustment for depressive symptoms or other potential bias factors. ${ }^{1}$ We have recently showed that sleep disturbances are very frequent in patients with bipolar disorder (BD), even when in euthymia. ${ }^{2}$ It is also known that $\mathrm{BD}$ is possibly the psychiatric diagnosis most frequently associated with suicidal behavior. ${ }^{3}$ To our knowledge, no previous study has specifically addressed this issue in this population. Therefore, we decided to investigate the relationship between sleep disruption and suicidal behavior in a sample of euthymic BD patients. We assessed 105 patients with BD (94 BD I + 11 BD II) using the MINI-International Neuropsychiatric Interview (MINIPlus), based on criteria set forth in the Diagnostic and Statistical Manual of Mental Disorders, 4th edition (DSMIV). ${ }^{4}$ The median age of our sample was 47 years and 81 patients $(77.1 \%)$ were female. Patients presented scores lower than 7 - euthymia - for both Hamilton and Young mood rating scales in the previous 4 weeks. ${ }^{5,6}$ Lifetime suicide attempts were assessed as previously described. ${ }^{2}$ We used scores from item 3 of the Hamilton Depression Rating Scale (HAM-D) to assess current suicidal behavior, including suicidal thoughts. ${ }^{5}$ Sleep quality was assessed by the Pittsburgh Sleep Quality Index (PSQI). ${ }^{7}$ We used the Statistical Package for the Social Sciences (SPSS) version 17.0 for statistical analyses. Pearson's chisquare test was used for categorical variables in bivariate analyses with a $5 \%$ significance level.

Table 1 shows the results of the bivariate analyses comparing suicidal behavior variables and sleep quality, assessed by the global PSQI score. We used PSQI - one of the most widely used subjective sleep quality instruments - to evaluate sleep quality. PSQI
\end{abstract}

is designed to assess sleep quality over a 1-month time interval. It contains 19 self-rated questions that generate 7 sub-component scores (subjective sleep quality, sleep latency, sleep duration, habitual sleep efficiency, sleep disturbances, use of sleeping medication, and daytime dysfunction) which are calculated and summed into a global score (0-21). No associations were found between the suicidal behavior variables, the PSQI global score (Table 1), and the 7 sub-components (data not shown). We found no significant associations with the suicidal behavior variables when treating the PSQI global score as a continuous variable. We also found no associations between sleep quality and the psychopharmacological medications prescribed by psychiatrists (data not shown).

It would be interesting to prospectively assess the same BD sample across the different phases of the disorder since euthymia could unquestionably have influenced the absence of association between poor sleep quality and current suicidal behavior in the present study. In fact, this finding is somewhat in agreement with previous research showing distinct suicidal behavior rates throughout the different phases of $\mathrm{BD}$, with significantly higher rates during mixed and depressive states. ${ }^{8,9}$

On the other hand, some studies have evaluated the potential link between sleep disturbances and suicidal behavior in patients with BD as secondary outcomes. ${ }^{10,11}$ A prior study found that sleep disturbance was associated with the number of previous suicide attempts in a sample of euthymic BD patients. ${ }^{10}$ However, sleep assessment was performed based on item 4 (reduced sleep) of the Montgomery-Åsberg Depression Rating Scale in that study. More recently, a nested case-control study using a large hospital database for self-harm admissions found 
Table 1 - Analysis of selected articles in systematic review

\begin{tabular}{|c|c|c|c|c|}
\hline \multirow[b]{2}{*}{ Suicidal behavior variables } & \multicolumn{2}{|c|}{ Sleep quality (PSQI global score) } & \multirow[b]{2}{*}{ Odds ratio $(95 \% \mathrm{CI})$} & \multirow[b]{2}{*}{$\mathbf{p}$} \\
\hline & Poor $(>5)$ & Poor $(\leq 5)$ & & \\
\hline Previous suicide attempt & 87 & 18 & & \\
\hline Yes & 46 & 7 & $1.76(0.63-4.97)$ & 0.325 \\
\hline No & 41 & 11 & 1 & \\
\hline Number of attempts & 87 & 18 & & \\
\hline 0 & 41 & 11 & 1 & \\
\hline $1-2$ & 30 & 5 & $1.61(0.51-5.12)$ & 0.420 \\
\hline$\geq 3$ & 16 & 2 & $2.15(0.43-10.78)$ & 0.354 \\
\hline Age at first attempt & 46 & 7 & & \\
\hline$\leq 25$ years & 18 & 2 & $1.61(0.28-9.19)$ & 0.594 \\
\hline$>25$ years & 28 & 5 & 1 & \\
\hline Violent method & 46 & 7 & & \\
\hline Yes & 16 & 2 & $1.33(0.23-7.66)$ & 0.747 \\
\hline No & 30 & 5 & 1 & \\
\hline Suicide ideation score (HAM-D) & 87 & 18 & & \\
\hline $1-4$ & 4 & 2 & $2.59(0.44-15.38)$ & 0.294 \\
\hline 0 & 83 & 16 & 1 & \\
\hline
\end{tabular}

HAM-D = Hamilton Depression Rating Scale; $95 \% C I=95 \%$ confidence interval; PSQI = Pittsburgh Sleep Quality Index.

that sleep disturbance was more common in BD cases than controls who self-harm. ${ }^{11}$ Unfortunately, euthymia was not an inclusion criteria for the BD group in that study. Moreover, sleep assessment was performed by review of medical records.

Several studies have reported the association of some sleep disturbances with increased suicide risk in different clinical samples, which could not be replicated in our study. Although the small sample size and the cross-sectional observation could be limitations to the present study, it may shed preliminary light on the scarcity of data relating to sleep disturbances and suicidal behavior in euthymic BD samples. Further studies with larger samples will be required to better address this important question. This would be particularly relevant because sleep disturbances are considered a potentially modifiable or preventable risk factor for suicide.

\section{Paulo Marcos Brasil Rocha, ${ }^{1}$ Fernando Silva Neves, ${ }^{1,2}$ Humberto Corrêa ${ }^{1,2}$}

1 Programa de Pós-Graduação em Neurociências, Instituto de Ciências Biológicas, Universidade Federal de Minas Gerais (UFMG), Belo Horizonte, MG, Brazil. 2 Departamento de Saúde Mental, Faculdade de Medicina, UFMG, Belo Horizonte, MG, Brazil.

\section{References}

1. Pigeon WR, Pinquart M, Conner K. Meta-analysis of sleep disturbance and suicidal thoughts and behaviors. J Clin Psychiatry. 2012;73:e1160-7.

2. Rocha PM, Neves FS, Corrêa H. Significant sleep disturbances in euthymic bipolar patients. Compr Psychiatry. 2013;54:1003-8.

3. Malloy-Diniz LF, Neves FS, de Moraes PH, De Marco LA, RomanoSilva MA, Krebs MO, et al. The 5-HTTLPR polymorphism, impulsivity and suicide behavior in euthymic bipolar patients. J Affect Disord. 2011:133:221-6.
4. Amorim P. Mini International Neuropsychiatric Interview (MINI): validação de entrevista breve para diagnóstico de transtornos mentais. Rev Bras Psiquiatr. 2000;22:106-15.

5. Hamilton M. A rating scale for depression. J Neurol Neurosurg Psychiatry. 1960;23:56-62.

6. Young RC, Biggs JT, Ziegler VE, Meyer DA. A rating scale for mania: reliability, validity and sensitivity. $\mathrm{Br} J$ Psychiatry. 1978;133:429-35.

7. Buysse DJ, Reynolds CF 3rd, Monk TH, Berman SR, Kupfer DJ. The Pittsburgh Sleep Quality Index: a new instrument for psychiatric practice and research. Psychiatry Res. 1989;28:193213.

8. Valtonen HM, Suominen K, Haukka J, Mantere O, Leppämäki S, Arvilommi $P$, et al. Differences in incidence of suicide attempts during phases of bipolar I and II disorders. Bipolar Disord. 2008; 10:588-96.

9. Isometsä E. Suicidal behaviour in mood disorders--who, when, and why? Can J Psychiatry. 2014;59:120-30.

10. Sylvia LG, Dupuy JM, Ostacher MJ, Cowperthwait CM, Hay AC Sachs GS, et al. Sleep disturbance in euthymic bipolar patients. J Psychopharmacol. 2012;26:1108-12.

11. Clements C, Jones S, Morriss R, Peters S, Cooper J, While D, et al. Self-harm in bipolar disorder: findings from a prospective clinical database. J Affect Disord, 2015;173:113-9.

\section{Correspondence:}

Paulo Marcos Brasil Rocha

Departamento de Saúde Mental, Faculdade de Medicina, Universidade Federal de Minas Gerais

Av. Professor Alfredo Balena, 190, sala 267

30130-100 - Belo Horizonte, MG - Brazil

Tel. : +55 (31) 3409.9785

E-mail: paulombrasil@gmail.com

Submitted Aug 17 2015, accepted for publication Jan 20 2016. No conflicts of interest declared concerning the publication of this article.

Financial support: Instituto Nacional de Ciência e Tecnologia de Medicina Molecular (INCT/CNPq/MCT, FAPEMIG), CNPq grant no. 473674/2009-2, FAPEMIG grant PPM-IV. Suggested citation: Rocha PM, Neves FS, Corrêa H. Sleep quality and suicidal behavior in euthymic bipolar patients [letter]. Trends Psychiatry Psychother. 2016;38(3):183-184. http://dx.doi.org/10.1590/2237-6089-2015-0046 